\title{
Hereditary Aspects of Decreased Hypoxic Response
}

\author{
D. D. Collins, C. H. Scoggin, C. W. Zwillich, and J. V. Weil, \\ Cardiovascular Pulmonary Research Laboratory and Division of Pulmonary \\ Sciences of the Department of Medicine, University of Colorado Medical Center, \\ Denver, Colorado 80262
}

\begin{abstract}
A в S T R A C T Decreased ventilatory responses to hypoxia and hypercapnia have been demonstrated in a variety of disorders; however, the etiology of these decreased drives remains virtually unknown. Recent observations have suggested a familial influence on hypoxic and hypercapnic ventilatory response, but it is unclear whether this influence is the result of hereditary or environmental influences. Therefore we measured the ventilatory response to isocapnic hypoxia (HVR) and hyperoxic hypercapnia in 12 pairs of identical and 12 pairs of nonidentical twins. Significant correlation $(P<0.01)$ was found for HVR within identical twin pairs but not within nonidentical twin pairs. Identical twins resembled each other more closely with respect to HVR than was the case for nonidentical twins $(P<0.0125)$. This was independent of body size, blood $\mathrm{PCO}_{2}$, or $\mathrm{pH}$. No such correlation could be found for ventilatory response to hyperoxic hypercapnia. It is concluded that hereditary influences affect HVR and it is speculated that such influences may play a role in clinical conditions characterized by decreased hypoxic ventilatory responses.
\end{abstract}

\section{INTRODUCTION}

The magnitude of ventilatory responses to hypoxia and hypercapnia is known to span a broad range in the normal population (1). In addition, decreased responses are commonly found in specific subgroups including long-distance runners (2), the Enga tribesmen of New Guinea (3), and in patients with idiopathic hypoventilation $(4,5)$. Decreased ventilatory drive during hypercapnia has also been demonstrated in hypoventilating patients with chronic obstructive pulmonary disease when breathing effort has been assessed as inspiratory work (6), diaphragmatic electromylogram

Dr. Scoggin is a Teaching and Research Scholar, American College of Physicians. Dr. Zwillich is a recipient of a $\mathrm{Na}$ tional Institutes of Health Research Career Development Award.

Received for publication 24 June 1977 and in revised form 2 February 1978.
(7), or inspiratory occlusion pressure (8), and contrasts with the near-normal values found in patients with similar degrees of obstruction, but with normal ventilation. The etiology of decreased ventilatory drives remains largely unknown.

Recently it has been suggested that familial influences play an important role in the determination of ventilatory drives. In studies of patients with unexplained respiratory failure in whom ventilatory responses to hypoxia were found to be decreased, similarly decreased responses were found in healthy family members $(4,5)$. Furthermore, Saunders et al. have shown a correlation between hypercapnic ventilatory responses seen in championship swimmers and their siblings (9), and we have found decreased hypoxic ventilatory responses in successful endurance runners and in their nonathletic parents and siblings (10).

All these observations support a familial effect on the drives to breathe; however, it is not clear whether these decreased drives are the result of factors within the environment or are under hereditary influence. Therefore, to investigate the importance of heredity we studied the ventilatory responses to hypoxia and to hypercapnia in nonidentical twins (same environment, different genes) and in identical twins (same environment, same genes).

\section{METHODS}

Subjects for study consisted of 12 pairs of identical and 12 pairs of nonidentical twins. Both members of nonidentical twin pairs were of the same sex. Nonidentical twin pairs ranged in age from 13 to $26 \mathrm{yr}$ (average $17.2 \mathrm{yr}$ ) and identical twin pairs from 12 to $18 \mathrm{yr}$ (average $14.5 \mathrm{yr}$ ). All subjects were healthy with no history of pulmonary disease, were taking no medications, and were native to low altitude. All twin pairs with a single exception shared a common residence up to the time of the study. All subjects gave consent, and study procedures were approved by the University of Colorado Medical Center Human Research Committee.

Zygosity (identical vs. nonidentical status) was determined by general similarity of appearance, hair color, eye color, ear lobe attachment, hand prints, and a panel of blood, urine, and salivary antigens. Marked discordance was present in all twins classified as nonidentical. 
Ventilatory responses were measured with the subject reclining in a semidarkened room, with television as a visual and auditory distraction. All subjects were studied in the fasting basal state. Hypoxic ventilatory response was measured during progressive isocapnic hypoxia (11). Briefly the subject breathed through a Rudolph respiratory valve (Warren E. Collins, Inc., Braintree, Mass.) from which end-tidal oxygen tension $\left(\mathrm{PA}_{\mathrm{O}_{2}}\right)^{1}$ was measured with a fuel cell oxygen analyzer (12). Similarly, end-tidal carbon dioxide tension $\left(\mathrm{PA}_{\mathrm{CO}_{2}}\right)$ was monitored with an infra-red analyzer (Beckman LB-1 Beckman Instruments, Inc., Fullerton, Calif.) and minute ventilation $\left(\dot{\mathrm{V}}_{\mathrm{E}}\right)$ was measured with a pneumotachograph and Statham pressure transducer (PM 97-TC, Statham Instruments, Inc., Oxnard, Calif.) calibrated against a Tissot spirometer. Gas analyzers were calibrated with gases analyzed by the Scholander technique (13). Progressive hypoxia was induced over approximately $8-10 \mathrm{~min}$ by the addition of nitrogen to a reservoir bag filled with $30 \%$ oxygen from which the subject breathed such that $\mathrm{PA}_{\mathrm{O}_{2}}$ was decreased from a starting value of $130 \mathrm{~mm} \mathrm{Hg}$ to a final level of $40 \mathrm{~mm} \mathrm{Hg}$. Throughout this period $\mathrm{PA}_{\mathrm{CO}_{2}}$ was kept constant at resting values by the addition of $100 \% \mathrm{CO}_{2}$ to the inspired gas. Because small changes in $\mathrm{PA}_{\mathrm{CO}_{2}}$ have significant effects on hypoxic ventilatory response (11), resting $\mathrm{PA}_{\mathrm{CO}_{2}}$ was monitored and testing was begun only when observers were satisfied with a stable value of $\mathrm{PA}_{\mathrm{CO}_{2}}$ had been obtained which was unchanged over several trials. Since arterial $\mathrm{pH}$ can influence ventilatory response, arterialized venous blood (14) was analyzed in each subject to assure that end-tidal $\mathrm{PA}_{\mathrm{CO}_{2}}$ values represented an accurate reflection of arterial $\mathrm{pH}$ and subjects were in normal acidbase balance (average pH $=7.398 \pm 0.0040)(\mathrm{SEM})$.

Curves relating $\dot{\mathrm{V}}_{\mathrm{E}}$ to $\mathrm{PA}_{\mathbf{O}_{2}}$ are hyperbolic in shape and analyzable by a simple hyperbolic equation: $\dot{\mathrm{V}}_{\mathrm{E}}=\dot{\mathrm{V}}_{0}+\mathrm{A} /\left(\mathrm{PA}_{\mathrm{O}_{2}}-32\right)$ (11). $\dot{V}_{\mathrm{E}}$ is minute ventilation (BTPS, body temperature, pressure, saturated with water), $\mathrm{PA}_{\mathrm{O}_{2}}$ is alveolar oxygen tension in $\mathrm{mm} \mathrm{Hg}$, and $\dot{V}_{0}$ is the asymptote for ventilation obtained by extrapolation. The parameter A provides a useful, sensitive determination of the shape of the curve within the observed data range such that a high value for $A$ denotes a vigorous ventilatory response to hypoxia and a low value a blunted response. Minute ventilation calculated from this equation in within $4 \%$ of the measured value (15).

Ventilatory response to hypercapnia was measured with a simple rebreathing technique. A 5-liter rebreathing circuit containing $30 \%$ oxygen was used. Thus, hypoxia was prevented and the response measured was that to hyperoxic hypercapnia. Analyzers and transducers employed were the same as mentioned above. Utilizing this system, a rise in $\mathrm{PA}_{\mathrm{CO}_{2}}$ of approximately $10 \mathrm{~mm} \mathrm{Hg}$ over control was produced over approximately $10 \mathrm{~min}$. The ventilatory response to hypercapnia is linear and described by the equation $\dot{\mathrm{V}}_{\mathrm{E}}=\mathrm{S}\left(\mathrm{PA}_{\mathrm{CO}_{2}}\right.$ - B) where $B$ is the extrapolated intercept on the abscissa $\left(\mathrm{PA}_{\mathrm{CO}_{2}}\right)$ axis and $\mathrm{S}$ is the slope of the line expressed as the change in ventilation (BTPS) per $\mathrm{mm} \mathrm{Hg}$ change in $\mathrm{PA}_{\mathrm{CO}_{2}}$. This method differs from that of Read (16) in that no $\mathrm{CO}_{2}$ is initially present in the system and data collection begins when inspired $\mathrm{CO}_{2}$ approaches the initial $\mathrm{PA}_{\mathrm{CO}_{2}}$. This technique produces linear responses with slopes similar to those obtained with Read's method but with slightly lower intercepts (1).

Data was analyzed by standard methods for experiments comparing identical and nonidentical twins (17).

${ }^{1}$ Abbreviations used in this paper: BTPS, body temperature, pressure, saturated with water; $\mathbf{P A}_{\mathrm{CO}_{2}}$, alveolar carbon dioxide tension; $\mathrm{PA}_{\mathrm{O}_{2}}$, alveolar oxygen tension; $\mathrm{PCO}_{2}$, pressure of carbon dioxide; $\dot{\mathrm{V}}_{\mathrm{E}}$, minute ventilation.

\section{RESULTS}

Anthropometric data, results of measurement of hypoxic and hypercapnic ventilatory responses and blood gas acid-bases status are shown in Table I. Ventilatory responses to hypoxia were similar for both members of identical twin pairs such that when the value for one twin was plotted against that of the other, the results were distributed along the line of identity (Fig. 1). No such distribution was found for nonidentical twins. For this and subsequent figures twins were allocated to $x$ and $y$ on a random basis. Changes in order would influence the tightness of distribution in such a plot but not the tendency of data to distribute along the line of identity. The techniques used for statistical analysis of the data are free of any order effect. Hypoxic responses for each group of data were subjected to a one-way random effects analysis of variance in order to estimate the variability between twin pairs and the variability between individuals within each twin pair (17). The results are shown in Table II. The intraclass correlation coefficient of 0.76 for identical twins corresponds to a $P<0.01$ and indicates that hypoxic responses for the members of identical twin pairs are significantly correlated. In contrast no significant correlation was found between members of nonidentical twin pairs. Direct comparison of within pair variability for the two classes of twins indicates that the variability within twin pairs was significantly smaller $(P$ $<0.0125)$ for identical twins than for nonidentical twins, indicating that identical twins are more homogeneous with respect to hypoxic ventilatory response (A) than nonidentical twins. Variability between twin pairs was similar for both groups. In the case of hypercapnic ventilatory response no significant correlation was found between members of either identical or nonidentical twin pairs (Fig. 2). No correlation was found for either identical or nonidentical twin pairs' heart rate response to hypoxia.

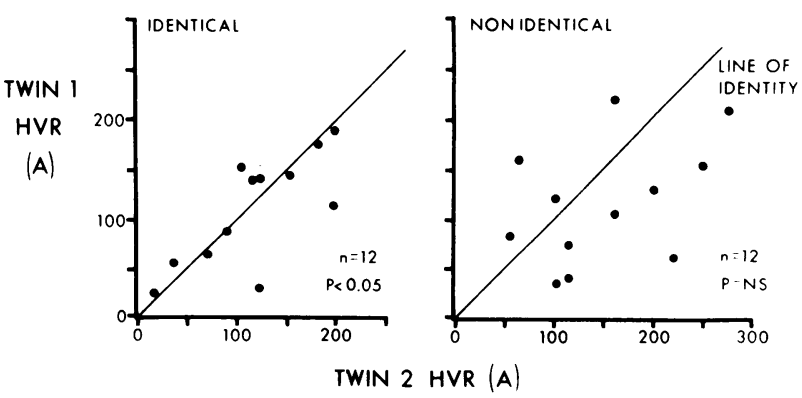

Figure 1 Correlation was found between hypoxic ventilatory responses (HVR) (A) for identical twins (left) but not nonidentical twins (right). The variability within twin pairs was significantly smaller $(P<0.0125)$ for identical twins than nonidentical twins, indicating identical twins are more homogeneous with respect to A than nonidentical twins. 
TABLE I

Ventilatory Responses to Hypoxia (A) and Hypercapnia (S) in Identical and Nonidentical Twins

\begin{tabular}{|c|c|c|c|c|c|c|c|c|c|c|c|}
\hline \multirow[b]{2}{*}{ Twin pair } & \multirow[b]{2}{*}{ Sex } & \multirow[b]{2}{*}{ Age. } & \multirow{2}{*}{$\begin{array}{c}\text { Body } \\
\text { surface } \\
\text { area }\end{array}$} & \multirow[b]{2}{*}{$\mathbf{A}$} & \multirow{2}{*}{$\begin{array}{c}\text { A/Body } \\
\text { surface } \\
\text { area }\end{array}$} & \multirow[b]{2}{*}{ vo } & \multirow[b]{2}{*}{$\mathrm{PA}_{\mathrm{AO}_{2}}$} & \multirow[b]{2}{*}{$\mathbf{s}$} & \multirow[b]{2}{*}{ B } & \multicolumn{2}{|c|}{ Arterialized venous } \\
\hline & & & & & & & & & & $\mathrm{PaCO}_{2}$ & $\mathrm{pH}$ \\
\hline & & $y r$ & $M^{2}$ & BTPS & & liters/min & $m m \mathrm{Hg}$ & BTPS & $m m \mathrm{Hg}$ & $m m \mathrm{Hg}$ & \\
\hline \multicolumn{12}{|l|}{ Identical twins } \\
\hline la & $\mathbf{F}$ & 13 & 1.38 & 142 & 103 & 5.12 & 33.4 & 1.84 & 28.8 & 34.6 & 7.393 \\
\hline $1 \mathrm{~B}$ & $\mathbf{F}$ & 13 & 1.36 & 124 & 91 & 7.15 & 34.9 & 2.68 & 32.2 & 32.6 & 7.418 \\
\hline $2 a$ & $\mathbf{F}$ & 14 & 1.41 & 142 & 101 & 6.66 & 31.6 & 1.92 & 28.8 & 27.6 & 7.425 \\
\hline $2 B$ & $\mathbf{F}$ & 14 & 1.38 & 154 & 112 & 5.18 & 31.8 & 2.41 & 31.2 & 28.8 & 7.405 \\
\hline $3 a$ & $\mathbf{F}$ & 25 & 1.78 & 144 & 81 & 4.53 & 35.1 & 1.73 & 31.0 & 34.5 & 7.390 \\
\hline $3 B$ & $\mathbf{F}$ & 25 & 1.82 & 129 & 71 & 5.30 & 33.1 & 2.75 & 33.4 & 34.0 & 7.375 \\
\hline $4 a$ & $\mathbf{F}$ & 15 & 1.55 & 59 & 38 & 6.29 & 34.4 & 1.86 & 32.7 & - & - \\
\hline $4 B$ & $\mathbf{F}$ & 15 & 0.88 & 37 & 42 & 5.09 & 35.4 & 1.84 & 35.5 & 40.2 & 7.405 \\
\hline $5 a$ & $\mathbf{F}$ & 14 & 1.60 & 65 & 41 & 4.37 & 34.2 & 2.23 & 35.5 & - & - \\
\hline $5 B$ & $\mathbf{F}$ & 14 & 1.58 & 67 & 42 & 4.29 & 32.9 & 1.84 & 33.2 & - & - \\
\hline $6 a$ & $\mathbf{F}$ & 22 & 1.70 & 33 & 108 & 4.50 & 3.6 & 3.91 & 33.2 & 32.7 & 7.407 \\
\hline $6 \mathrm{~B}$ & $\mathbf{F}$ & 22 & 1.72 & 123 & 71 & 3.97 & 33.5 & 3.79 & 35.3 & 31.6 & 7.415 \\
\hline $7 a$ & $\mathbf{F}$ & 17 & 1.62 & 151 & 93 & 4.65 & 34.6 & 2.53 & 31.2 & 29.9 & 7.390 \\
\hline $7 \mathrm{~B}$ & $\mathrm{~F}$ & 17 & 1.87 & 104 & 55 & 5.39 & 30.2 & 2.77 & 30.4 & 28.8 & 7.396 \\
\hline $8 a$ & $\mathbf{M}$ & 21 & 1.79 & 28 & 16 & 4.93 & 33.7 & 1.94 & 35.4 & 37.0 & 7.385 \\
\hline $8 B$ & $\mathbf{M}$ & 21 & 1.82 & 15 & 8 & 5.89 & 38.1 & 2.69 & 40.2 & 37.1 & 7.398 \\
\hline $9 a$ & $\mathbf{M}$ & 13 & 1.58 & 178 & 112 & 4.85 & 33.2 & 3.49 & 31.2 & 31.5 & 7.379 \\
\hline $9 B$ & $\mathbf{M}$ & 13 & 1.64 & 182 & 111 & 5.51 & 30.8 & 8.27 & 35.3 & 32.1 & 7.402 \\
\hline $10 a$ & $\mathbf{M}$ & 26 & 1.92 & 114 & 59 & 5.92 & 36.2 & 2.04 & 32.8 & 33.5 & 7.420 \\
\hline $10 \mathrm{~B}$ & $\mathbf{M}$ & 26 & 1.84 & 198 & 108 & 5.62 & 33.2 & 4.06 & 32.3 & 39.2 & 7.275 \\
\hline $11 a$ & $\mathbf{F}$ & 10 & 1.02 & 80 & 78 & 4.23 & 29.5 & 2.34 & 30.6 & 32.5 & 7.392 \\
\hline $11 B$ & $\mathrm{~F}$ & 10 & 1.06 & 83 & 78 & 3.46 & 31.5 & 2.35 & 32.4 & 30.3 & 7.402 \\
\hline $12 \mathrm{a}$ & $\mathbf{M}$ & 18 & 1.98 & 184 & 93 & 6.22 & 33.5 & 3.34 & 34.2 & 31.1 & 7.405 \\
\hline $12 B$ & $\ddot{\mathbf{M}}$ & 18 & 1.92 & 198 & 103 & 4.43 & 33.1 & 3.76 & 34.2 & 30.6 & 7.405 \\
\hline \multicolumn{12}{|c|}{ Nonidentical twins } \\
\hline la & $\mathbf{F}$ & 15 & 1.66 & 213 & 129 & 4.71 & 32.8 & 2.63 & 26.2 & 30.6 & 7.438 \\
\hline $1 \mathrm{~B}$ & F & 15 & 1.60 & 278 & 174 & 5.74 & 30.6 & 2.00 & 26.7 & 27.8 & 7.432 \\
\hline $2 a$ & $\mathbf{M}$ & 16 & 1.93 & 40 & 21 & 7.17 & 34.1 & 2.01 & 33.5 & 36.0 & 7.370 \\
\hline $2 B$ & $\mathbf{M}$ & 16 & 1.95 & 118 & 61 & 5.54 & 32.4 & 2.68 & 35.9 & 32.8 & 7.405 \\
\hline $3 a$ & $\mathbf{M}$ & 12 & 1.53 & 86 & 56 & 4.59 & 33.8 & 3.45 & 37.4 & 30.5 & 7.390 \\
\hline $3 B$ & M & 12 & 1.37 & 55 & 40 & 6.39 & 34.1 & 2.75 & 34.1 & 33.0 & 7.365 \\
\hline $4 a$ & $\mathrm{~F}$ & 12 & 1.57 & 123 & 78 & 5.36 & 32.5 & 2.25 & 32.5 & 33.4 & 7.405 \\
\hline $4 B$ & $\mathrm{~F}$ & 12 & 1.79 & 101 & 56 & 4.66 & 33.6 & 2.06 & 33.7 & 28.8 & 7.355 \\
\hline $5 a$ & $\mathrm{~F}$ & 17 & 1.76 & 75 & 43 & 9.58 & 35.1 & 1.79 & 29.2 & 31.6 & 7.368 \\
\hline $5 B$ & $\mathbf{F}$ & 17 & 1.77 & 115 & 65 & 6.66 & 34.4 & 1.57 & 29.5 & 30.0 & 7.385 \\
\hline $6 a$ & $F$ & 12 & 1.31 & 163 & 124 & 6.54 & 32.4 & 2.37 & 30.2 & 37.3 & 7.404 \\
\hline $6 \mathrm{~B}$ & $\mathrm{~F}$ & 12 & 1.36 & 201 & 148 & 4.20 & 33.5 & 2.58 & 29.4 & - & - \\
\hline $7 a$ & $\mathbf{F}$ & 11 & 0.91 & 155 & 171 & 4.23 & 31.5 & 2.74 & 31.3 & 31.0 & 7.427 \\
\hline $7 \mathrm{~B}$ & $F$ & 11 & 0.97 & 249 & 260 & 2.69 & 33.1 & 2.55 & 31.7 & 33.0 & 7.405 \\
\hline $8 a$ & $F$ & 15 & 1.67 & 104 & 62 & 3.46 & 33.1 & 2.12 & 31.4 & 32.5 & 7.402 \\
\hline $8 B$ & $\mathrm{~F}$ & 15 & 1.79 & 161 & 90 & 5.01 & 35.0 & 2.16 & 33.7 & - & - \\
\hline $9 a$ & $F$ & 12 & 1.46 & 160 & 110 & 5.24 & 31.3 & 2.21 & 30.3 & 29.2 & 7.365 \\
\hline $9 \mathrm{~B}$ & $\mathbf{F}$ & 12 & 1.43 & 74 & 52 & 5.68 & 32.6 & 1.63 & 30.2 & 35.7 & 7.388 \\
\hline $10 \mathrm{a}$ & $\mathbf{M}$ & 18 & 2.05 & 64 & 31 & 7.67 & 37.5 & 2.96 & 35.8 & 37.3 & 7.385 \\
\hline $10 \mathrm{~B}$ & $\mathbf{M}$ & 18 & 1.80 & 219 & 121 & 10.57 & 34.0 & 3.69 & 32.8 & 32.1 & 7.415 \\
\hline $11 a$ & $\mathbf{M}$ & 17 & 1.86 & 221 & 118 & 3.70 & 34.1 & 1.98 & 29.4 & 32.5 & 7.400 \\
\hline $11 B$ & $\mathbf{M}$ & 17 & 1.85 & 161 & 87 & 5.14 & 34.4 & 3.08 & 33.6 & 35.5 & 7.395 \\
\hline $12 \mathrm{a}$ & $\mathbf{M}$ & 14 & 1.62 & 38 & 24 & 6.66 & 35.3 & 2.21 & 33.7 & 34.5 & 7.398 \\
\hline $12 B$ & $\mathbf{M}$ & 14 & 1.84 & 104 & 56 & 9.31 & 31.3 & 5.74 & 32.5 & 30.2 & 7.390 \\
\hline
\end{tabular}


TABLE II

Variance Components for Two Types of Twins

\begin{tabular}{lccl}
\hline \multicolumn{1}{c}{ Variance component } & $\begin{array}{c}\text { Identical } \\
\text { twins }\end{array}$ & $\begin{array}{c}\text { Nonidentical } \\
\text { twins }\end{array}$ & Difference \\
\hline Between pairs $\left(\sigma_{\mathrm{B}}{ }^{2}\right)$ & 2,498 & 1,884 & $P=\mathrm{NS}$ \\
Within pairs $\left(\sigma_{\mathrm{W}}{ }^{2}\right)$ & 789 & 2,761 & $P<0.0125$ \\
Total & 3,287 & 4,645 & \\
$\begin{array}{l}\text { Intra class correlation } \\
\text { coefficient }\end{array}$ & 0.76 & 0.41 & \\
\hline
\end{tabular}

It could be that ventilatory response to hypoxia was correlated in identical twins because of similarity of body size, a known determinant of the magnitude of hypoxic ventilatory response (1). However, when hypoxic response was corrected for body size by dividing the parameter $\mathrm{A}$ by body surface area, hypoxic responses remained correlated in identical twins and uncorrelated in nonidentical twins (Fig. 3).

Because hypoxic responses are influenced by acidbase chemistry (11) (augmented by acidosis and decreased by alkalosis) we looked for intrapair relationships of blood pressure of carbon dioxide $\left(\mathrm{PCO}_{2}\right)$ and $\mathrm{pH}$. Significant correlation between pair members was found for blood $\mathrm{PCO}_{2}$ (Fig. 4) in identical but not in nonidentical twins indicating that alveolar ventilation is more similar in identical than in nonidentical twins. The similarity of $\mathrm{P}_{\mathrm{CO}_{2}} \mathrm{~S}$ raises the question whether this could be influencing hypoxic responses. This is unlikely. Hypoxic response is influenced by pH, not by the $\mathrm{PCO}_{2}$ per se (18). Thus, acid-base chemistry does not appear to explain the findings. The $\mathrm{pH}$ of arterialized venous blood showed no correlation between twin pair members for either the identical or nonidentical group.

\section{DISCUSSION}

We found ventilatory responses to hypoxia to be similar in identical twin pairs and dissimilar in nonidentical twins, even though both types of twins shared a common environment. This supports the idea that hereditary factors have important influences on ventilatory responsiveness to at least one chemical stimulus, hypoxia.

Familial clustering of depressed ventilatory responses to hypoxia has been described in parents and siblings of patients with unexplained hypoventilation and in the immediate nonathletic family members of successful endurance athletes (10). It might be argued that these familial clusters of decreased hypoxic response in family members who are genetically related, but not identical, is at variance with the lack of demonstrated similarity in the nonidentical twins who also have genetic relationship. The difference may be that in the studies of patients, athletes and their relatives, an extreme end of the spectrum of ventilatory responses was being examined, a situation which optimizes the likelihood of demonstrating a genetic trait. In the present study no attempt was made to select twins with extreme ventilatory responses and hence the values were evenly distributed over the normal range. Under these conditions, maximum genetic influence would be necessary to demonstrate an effect. Although we found a genetic influence, we cannot speculate at this time as to a pattern of inheritance.

We found no hereditary influence on the ventilatory response to hypercapnia. This is consistent with the study of Arkinstall et al. (19) who also measured hypercapnic ventilatory responses in identical and nonidentical twins, and were unable to demonstrate a hereditary influence on the ventilatory response to

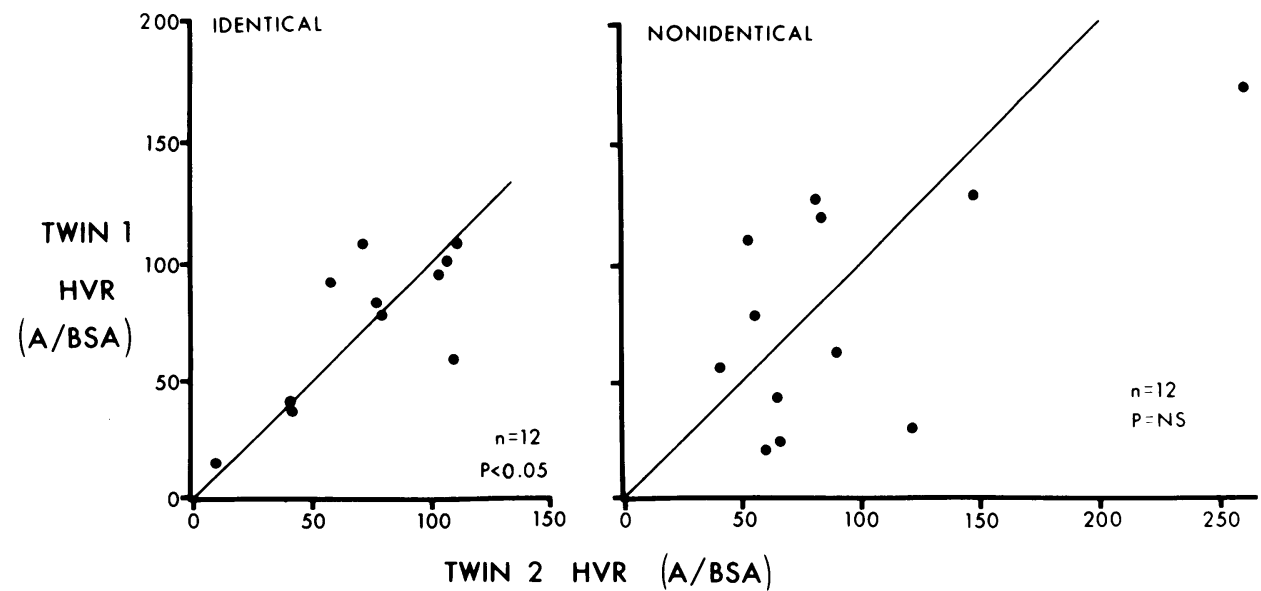

FIGURE 2 Correlation of hypoxic ventilatory responses (HVR) for identical twins was maintained when corrected for body size by dividing response by body surface area $\left(\mathrm{M}^{2}\right)$. 

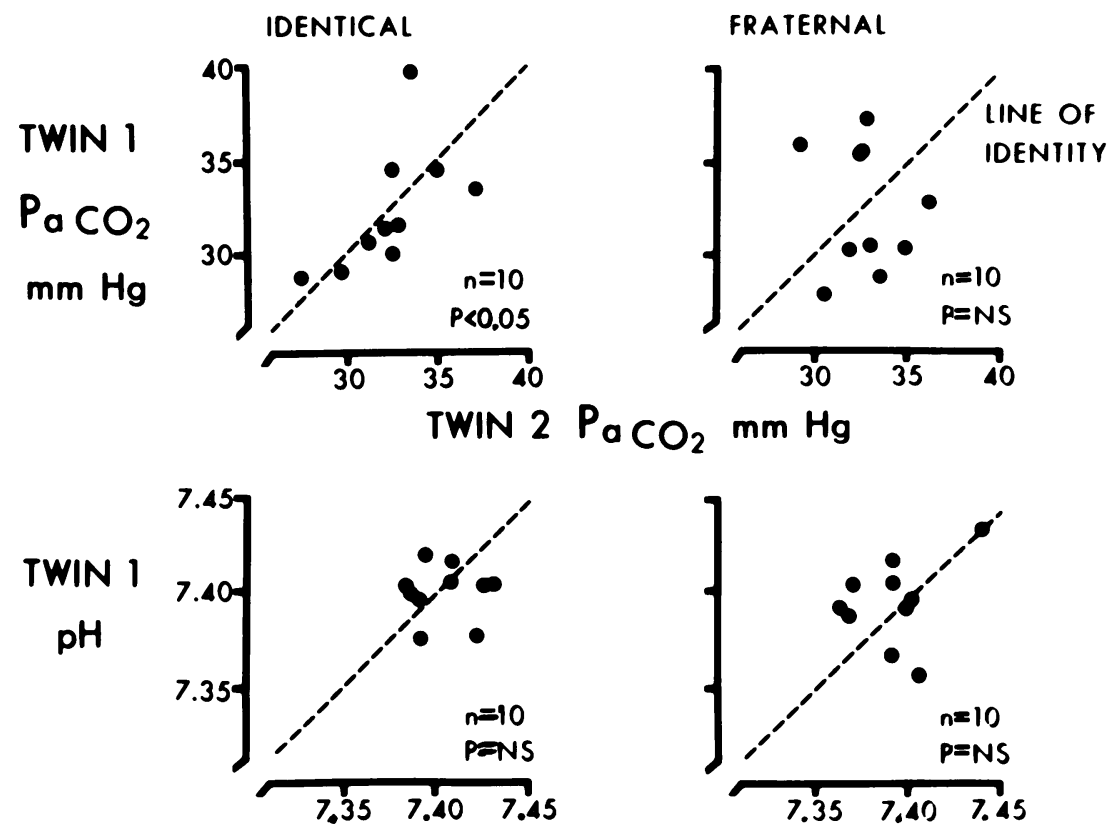

TWIN $2 \mathrm{pH}$

Figure 3 Resting arterialized venous $\mathrm{PaCO}_{2}$ and $\mathrm{pH}$ in identical and nonidentical twins. Significant correlation $(P<0.05)$ was found for blood $\mathrm{PaCO}_{2}$ in identical twins (upper left), but not in nonidentical twins (upper right); however, no correlation could be demonstrated for $\mathrm{pH}$ (lower left and right).

hypercapnia, although they did find an effect on breathing frequency and tidal volume responses to hypercapnia. Unfortunately, technical aspects of the system used for data acquisition precluded an examination of frequency and tidal volume aspects of hypoxic and hypercapnic responses in the present study.

The finding that genetic factors influence hypoxic but not hypercapnic responses provides a clue to the potential mechanism involved. Ventilatory responses to hypoxia are exclusively sensed by the carotid bodies in man (20-22) while responses to hypercapnia are generally held to be mediated by both the carotid bodies and, to an even larger extent, by the central medullary chemoreceptor. Thus, a relatively selective effect on hypoxic response suggests that the genetic factors are related either to carotid body responsiveness itself or to the central nervous system processing of signals coming from the carotid body. It is possible that a hereditary effect mediated through the carotid body or its central connections also exists for the hypercapnic ventilatory response, but because only a portion of that response is dependent upon the peripheral arterial chemoreceptors, the effect may be too small to demonstrate with the techniques and number of subjects studied. That genetic factors influencing hypercapnic response may exist is suggested by the observation of ethnic and familial clusters of de- creased hypercapnic ventilatory response in the Enga tribesmen of New Guinea (3), patients with unexplained hypoventilation $(4,5)$, and in swimmers (9), although environmental influences could not be excluded.

These studies do not provide clues to the genetic mode of transmission (dominant vs. recessive, monovs. polygenic). They also leave unanswered questions concerning the locus at which genetic factors influence

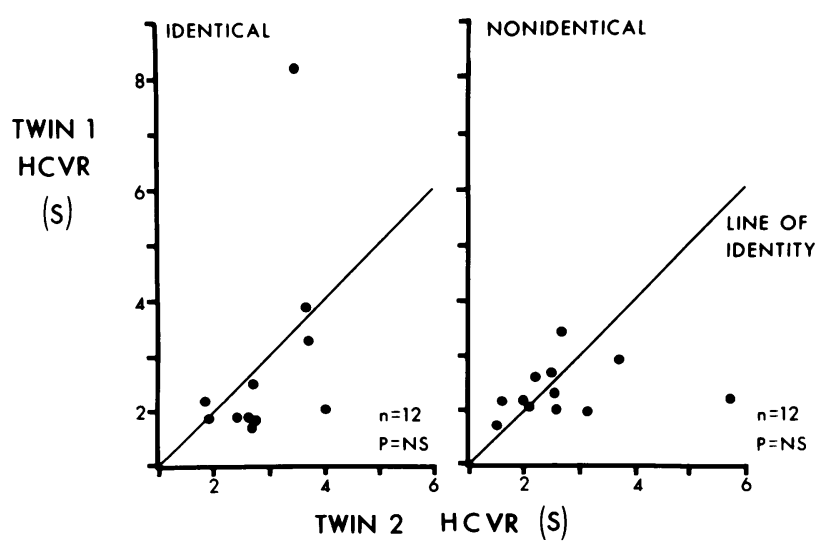

FIGURE 4 No correlation was found for either identical or nonidentical twins' ventilatory response to hypercapnia (HCVR). 
ventilatory control. Whether such efforts operate on the carotid body itself, or influence central signal processing remains unresolved. In theory, effects on pulmonary mechanics could also play a role but the constancy of the hypoxic ventilatory response in the face of alterations in breathing load (23) makes this last possibility unlikely.

We speculate that genetic factors may account for the diversity of ventilatory responses to hypoxia and hypercapnia observed in the normal population and may account for familial clusters of such decreased responses in athletes and in patients with unexplained hypoventilation. Growing evidence suggests that decreased ventilatory drive is closely related to, and may account for, hypoventilation in chronic obstructive pulmonary disease, and may constitute the factor which separates "fighter" from "nonfighter" (6-8). These diverse clinical profiles may reflect the effects of lung damage combined with differing levels of preexisting ventilatory drive. In this way, genetic factors may be important determinants of the clinical features in patients with abnormal lungs.

\section{ACKNOWLEDGMENTS}

The authors wish to thank Coach Lee Courcamp of Arvada West High School, and Dr. Phillip Weiser. Gary O. Zerbe, Ph.D., and Denise Roe gave invaluable statistical assistance.

This investigation was supported by Training grants HL 05973 and T32 HL 07085 and grant HL 14985, all from the National Institutes of Health.

\section{REFERENCES}

1. Hirshman, C. A., R. E. McCullough, and J. V. Weil. 1975. Normal values for hypoxic and hypercapnic ventilatory drives in man. J. Appl. Physiol. 38: 1095-1098.

2. Byrne-Quinn, E., J. V. Weil, I. E. Sodal, G. F. Filley, and R. F. Grover. 1971. Ventilatory control in the athlete. J. Appl. Physiol. 30: 91-98.

3. Beral, V., and D. J. C. Read. 1971. Insensitivity of respiratory center to carbon dioxide in Enga people of New Guinea. Lancet. II: 1290-1294.

4. Hudgel, D. W., and J. V. Weil. 1974. Asthma associated with decreased hypoxic ventilatory drive. Ann. Intern. Med. 80: 622-625.

5. Moore, C. G., and C. W. Zwillich, J. Battaglia, E. K. Cotton, and J. V. Weil. 1976. Respiratory failure associated with familial depression of ventilatory response to hypoxia and hypercarbia. 1976. N. Engl. J. Med. 295: $861-865$.

6. Lane, D. J., and J. B. L. Howell. 1970. Relationship between sensitivity to carbon dioxide and clinical features in patients with chronic airways obstruction. Thorax. 25: $150-159$.

7. Lourenco, R. V., and J. M. Miranda. 1968. Drive and performance of the ventilatory apparatus in chronic obstructive lung disease. N. Engl. J. Med. 279: 53-59.

8. Matthews, A. W., and J. B. L. Howell. 1976. Assessment of responsiveness to carbon dioxide in patients with chronic airways obstruction by rate of isometric inspiratory pressure development. Clin. Sci. Mol. Med. 50: 199-205.

9. Saunders, N. A., S. R. Leeder, and A. S. Rebuck. 1976. Ventilatory response to carbon dioxide in young athletes; a family study. Am. Rev. Respir. Dis. 113: 497-502.

10. Scoggin, C. H., R. D. Doekel, M. H. Kryger, C. W. Zwillich, and J. V. Weil. 1976. Familial aspects of decreased hypoxic drive in endurance athletes. Clin. Res. 24: 389A. (Abstr.)

11. Weil, J. V., E. Byrne-Quinn, I. E. Sodal, W. O. Friesen, B. Underhill, G. F. Filley, and R. F. Grover. 1970. Hypoxic ventilatory drive in normal man. J. Clin. Invest. 49: 1061-1072.

12. Weil, J. V., I. E. Sodal, and R. P. Speck. 1967. A modified fuel cell for the analysis of oxygen concentration of gases. J. Appl. Physiol. 23: 419-422.

13. Scholander, P. F. 1947. Analysis of accuracy of estimation of respiratory gases in one-half cubic centimeter samples. J. Biol. Chem. 167: 235-250.

14. Forster, H. V., J. A. Dempsey, J. Thompson, E. Vidruk, and G. A. Dopico. 1972. Estimation of arterial $\mathrm{Po}_{2}$, $\mathrm{PCO}_{2}, \mathrm{pH}$, and lactate from arterialized venous blood. J. Appl. Physiol. 32: 134-137.

15. Weil, J. V., E. Byrne-Quinn, I. E. Sodal, J. S. Kline, R. E. McCullough, and G. F. Filley. 1972. Augmentation of chemosensitivity during mild exercise in normal man. J. Appl. Physiol. 33: 813-819.

16. Read, D. J. C. 1967. A clinical method for assessing the ventilatory response to carbon dioxide. Australas Ann. Med. 16: 20-32.

17. Falconer, D. S. 1960. Introduction To Quantitative Genetics. The Roland Press Company, New York. 183-185.

18. Gabel, R. A., and R. B. Weiskoff. 1975. Ventilatory interaction between hypoxia and $\left(\mathrm{H}^{+}\right)$at chemoreceptors in man. J. Appl. Physiol. 39: 292-296.

19. Arkinstall, W. W., K. Nirmel, V. Klissouras, and J. Milic-Emili. 1974. Genetic differences in the ventilatory response to inhaled $\mathrm{CO}_{2}$. J. Appl. Physiol. 36: 6-11.

20. Guz, A., M. I. M. Noble, J. G. Widdicombe, D. Trenchard, and W. W. Mushin. 1966. Peripheral chemoreceptor block in man. Respir. Physiol. 1: 38-40.

21. Holton, P., and J. B. Wood. 1965. The effects of bilateral removal of the carotid bodies and denervation of the carotid sinuses in two human subjects. J. Physiol. (Lond.). 181: 365-378.

22. Wade, J. G., C. P. Larson, R. F. Hickey, W. K. Ehrenfeld, and J. W. Severinghaus. 1970. Effect of carotid endarterectomy on carotid chemoreceptor and baroreceptor function in man. N. Engl. J. Med. 282: 823-829.

23. Doell, D., M. Zutter, and N. R. Anthoisen. 1973. Ventilatory responses to hypercapnia and hypoxia at 1 and 4 ATA. Respir. Physiol. 18: 338. 